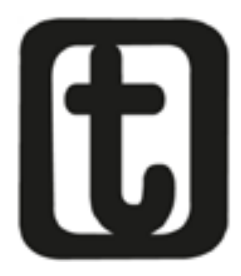

\title{
DISCURSO DE MARIETA KOIKE NA OFICINA NACIONAL DA ABEPSS (UFRJ, 2011)
}

The speech of Marieta Koike in the Abepss National Workshop

(UFRJ, 2011)

\section{Marieta Koike}

Estimada Presidente da Abepss, professora Claudia Monica;

Estimada companheira Carmelita Yazbeck, que comigo compartiIhou a gestão 94/95 coordenando o Cedepss;

Estimada companheira Ângela Amaral, aqui representando o Departamento de Serviço Social da UFPE;

Estimadas companheiras, prezados companheiros, estudantes, técnicos supervisores e demais presentes:

Compareço a esta solenidade para homenagear. Com isto deixo clara a parte que me toca neste evento.

Para minha alegria, o terceiro a que me faço presente em datas significativas para a Abepss. O primeiro, nos 50 anos da sua criação, em solenidade realizada na Uerj. O segundo, na UFPE, nos 70 anos do Serviço Social Brasileiro e 60 da entidade. Agora, na UFRJ, quando comemoramos 15 anos da aprovação do Currículo Mínimo do Curso de Serviço Social posteriormente designado como DIRETRIZES CURRICULARES, conforme a Lei da Reforma da Educação 
Superior, sancionada e publicada em 20 de dezembro de 1996.

Homenageados aqui são todas e todos que participaram do processo de elaboração das Diretrizes e vêem protagonizando sua implantação.

Homenageados são todas e todos que constituíram a Diretoria da Abess-Cedepss, no período da elaboração do projeto curricular.

Homenageados, portanto, são todas e todos que na trajetória da Abepss assumiram compromissos na condução político-acadêmica da nossa entidade acadêmica.

É aí onde me coloco. Uma, dentre tantas e tantos docentes eleitos por seus pares para coordenar as ações da Abepss e militar em seu campo de atuação.

Na caminhada de 65 anos, são muitos os que vivenciaram esta experiência - um contingente numeroso, tendo em vista que a estrutura da instituição agrega quadros docentes, discentes e supervisores técnicos representativos das unidades formadoras em âmbito nacional; característica da concepção democrática da Abepss consolidada na prática político-acadêmica.

É este contingente de dedicados militantes na luta pela formação profissional dos assistentes sociais que me vejo representar nesta Mesa. Formação capaz de dotar aos que buscam este campo de trabalho na sociedade de recursos teóricos, ético-operativos e político-organizacionais para tornar o exercício profissional um meio de fortalecer a vida e a luta dos trabalhadores.

Fazê-lo é uma honra e também um desafio.

Como é sabido, cada gestão na Abepss, tem seu plano de metas conforme as necessidades da formação naquele contexto histórico.

Nossa gestão, em dois períodos, 1994/95 e 1996/97, na época Abess-Cedeps, recebeu da assembleia geral que a elegeu a incumbência de instaurar o processo de revisão do currículo vigente, conhecido como currículo /82. 
A entidade tinha acúmulo e o momento era propício dado o nível de mobilização nas unidades de formação acadêmica e na categoria profissional.

O ano de 1993 havia sido marcante pelos intensos debates que culminaram na atualização do Código de Ética de 1986 e na sanção da Lei de Regulamentação da Profissão.

Desencadear o processo da revisão curricular naquela circunstancia era dar continuidade ao clima de mobilização existente.

A necessidade da inadiável revisão dos processos da formação estava dada e era fato a vontade coletiva de empreendê-la. O que por si só é um elemento primordial na empreitada de analisar criticamente a formação profissional e construir uma proposta capaz de aproximar formação e exercício profissional tendo a realidade social como fundamento.

O conjunto das unidades formadoras ia redefinir os rumos da formação em Serviço Social no país, num contexto de incalculáveis desafios. Igualmente, ia atender exigências do mercado de trabalho que passava por profundas transformações decorrentes da crise com a qual o capital se debatia desde o inicio dos anos 70 e preservar os avanços contidos no currículo/82, no Código de Ética Profissional, na Lei de Regulamentação da Profissão, na prática organizativa, sedimentando o exercício profissional para novos avanços.

A perspectiva de sociedade contida neste propósito ético-político-academico-profissional, referenciada na interlocução com a teoria social crítica, havia lançado o Serviço Social brasileiro em outro patamar.

E seria deste outro patamar que a Abess-Cedepss, na época, tinha o compromisso de encaminhar o processo de revisão.

Para fazê-lo democraticamente e com rigor teórico e ético-político, a assembleia geral das unidades acadêmicas indicou como eixo ordenador das ações a serem desenvolvidas a definição da direção social que iria presidir o novo projeto da formação profissional. Ou seja, ter clareza quanto à relação histórica da formação e do exercício profissional com a sociedade. 
Certamente não apreendi todas as questões e provavelmente não devo, também, ter apreendido toda a complexidade que as envolvia.

Contudo, logo percebi que o debate acerca da direção social da formação - que consumiu três dos quatro semestres que compõem cada gestão - revelava uma profusão de projetos profissionais e societários em disputa no meio acadêmico e profissional do Serviço Social no país.

Na coordenação do processo, cabia à Abepss criar condições para que o debate e o confronto de ideias ocorressem num clima de respeito e paciência pedagógica frente à pluralidade de concepções e posicionamentos teórico-metodológicos e político-operativos.

Lembremos que as ideologias da globalização, da pós-modernidade e do neoliberalismo disputavam proeminência sobre a teoria social crítica proclamando seu rotundo fracasso. O "fim da história" atestava a falta de serventia da teoria e do método que propunham desvendar e transformar a sociedade capitalista.

Para garantir o maior aprofundamento das questões suscitadas nas inúmeras oficinas que se realizavam Brasil afora, foi constituído um grupo de consultores representantes das regiões em que a Abepss se estrutura e estes asseguravam a pluralidade das ideias presentes, base para a construção de consensos e hegemonia.

Aqui faço um parêntesis para render homenagem a uma das consultoras: a querida e devotada militante professora Nobuco Kameyama, a quem numa assembleia da Abepss chamei de paradigmática. Ela, com seu jeito oriental e a fala mansa que era sua característica respondeu no microfone: - Marieta, logo agora, em plena crise dos paradigmas você me chama de paradgmática!

É pensando em Nobuquinho - como a chamávamos - que saúdo, reconheço e agradeço o empenho e o compromisso das consultoras e consultores da Abepss no processo da elaboração das Diretrizes Curriculares.

Não vou repetir o que já está dito em textos publicados recuperando os passos, etapas, questionamentos, produção teórica, im- 
passes e avanços do processo que se desenrolou em duas gestões seguidas.

Tenho, no entanto, uma pergunta que sempre me surpreende. Como foi possível Abess-Cedepss dar conta?

Como foi possível o projeto pedagógico chegar a termo considerando as históricas condições materiais da instituição e os grandes e complexos desafios presentes na realidade brasileira, latino-americana e, dizendo melhor, na totalidade dos países.

A seu modo, nas particularidades históricas de sua formação social, todos os países se defrontavam com os impactos da mais longa crise do capital.

O capitalismo se apresentava em outra fase de seu desenvolvimento histórico caracterizada por novas formas e meios de exploração do trabalho, transitando para o estabelecimento de outro padrão de sociabilidade burguesa.

Processo de "mudança abissal" como observou Harvey, que subverte e redefine os projetos ídeo-políticos, as relações sociais, as subjetividades e as práticas consolidadas na sociedade, estabelecendo outro modo de organização da vida social. E, como necessariamente ocorre, devendo torná-la hegemônica.

Nesse contexto, a condição de repensar criticamente a formação profissional, a universidade, a educação superior, as políticas sociais públicas, a concepção e o papel do Estado, as condições de trabalho, o Serviço Social e as demandas que o mercado de trabalho apresenta como expressão da Questão Social punha como necessário ponto de partida compreender criticamente a gênese, desdobramentos e as formas de enfrentamento da crise utilizadas pelas classes sociais e pelo Estado.

Hoje, dá para perceber com nitidez o quanto foi estratégico e pedagogicamente acertado aquele encaminhamento.

E aí já está parte da resposta à pergunta formulada.

O aprofundamento da natureza, das dimensões e impactos da 
crise, o debate do significado social da profissão e a análise do alcance sócio-histórico dos princípios da liberdade, equidade, democracia, justiça e do que representam na perspectiva da construção do projeto societário no qual ganhem efetividade iam aclarando o que poderia constituir eixos nucleadores do currículo, conteúdos programáticos e demais componentes que o projeto deveria contemplar.

A lógica curricular estabelecida é a expressão objetiva daquele acerto. Lógica curricular com direção social estratégica, com núcleos de fundamentação que articulam matérias, categorias teóricas e práticas pedagógicas calcadas na vida social e no caráter histórico do Serviço Social na divisão do trabalho na sociedade

Sem nenhum laivo de reificação, sem sombras de uma visão politicista, ufanista ou idealista, reafirmo, 15 anos depois, o que foi posto à apreciação e votação pelas unidades acadêmicas presentes à memorável assembleia de 08 de novembro de 1996, na Uerj.

Agora, existem problemas? Sim, existem.

Há questões, pontos, aspectos que carecem de maior explicitação. Necessita-se, sobretudo, de acompanhamento e avaliação continuada dos processos de implantação e implementação das Diretrizes, a exemplo da que foi realizada na gestão da Professora Ana Elizabete Mota, no décimo ano da aprovação das Diretrizes Curriculares.

Há carência, sobretudo, de ênfase na pesquisa acerca dos processos da formação acadêmico-profissional e das demandas ao Serviço Social face à realidade do país.

Igualmente é necessário desenvolver processos e mecanismos que favoreçam a efetiva articulação entre a graduação e a pós-graduação.

Sabe-se que para detectar os problemas, lacunas, impasses e também avanços, bastaria ouvir as unidades da formação acadêmica: docentes, estudantes, supervisores e, igualmente, as instituições empregadoras e os usuários do trabalho profissional dos assistentes sociais. 
Creio que os desafios de hoje à formação e ao exercício profissional sejam mais duros e complexos que os de 15 anos atrás.

A crise capitalista aprofundou-se e universalizou-se sob o predomínio do capital financeiro. O trabalho tornou-se mais precarizado e desvalorizado. Há menos demanda por trabalho vivo e um maior nível e novas formas de subordinação do trabalho.

A educação superior privatizada e banalizada como qualquer mercadoria e a universidade pública, a passos largos, prosseguem na lógica do empreendedorismo empresarial.

O movimento do capital favorece o crescimento exponencial das desigualdades sociais a despeito do aumento também exponencial da riqueza fornecendo substância ao recrudescimento da Questão Social e à barbarização das suas manifestações.

Ao lado disso, verifica-se uma baixa capacidade organizativa das entidades representativas dos direitos e interesses das classes trabalhadoras.

Realidade esta que atinge o Serviço Social, refletindo-se na formação e no exercício profissional, nos espaços laborais e nas relações dentro da categoria profissional, agora mais numerosa e com segmentos malformados. Isto é, formação massiva, de pouca qualidade, desencadeando acirrada competição entre os pares.

O pensamento crítico dá provas de que encolheu com a debandada de boa parte da intelectualidade para o campo do conservadorismo e da militância sindical para o aparelho do Estado.

Mas, como nos anos 90, no cenário aqui apenas esboçado, entidades como a Abepss se fazem cada vez mais estrategicamente necessárias.

Refiro-me a organizações com direção social vinculada ao fortalecimento dos direitos das classes trabalhadoras na perspectiva de construção de sociabilidade que resgate o trabalho como fundamento ontológico da vida social.

Entidades legitimadas e consolidadas na função de intelectual cole- 
tivo, dirigente e articuladora de ações que desvelem as artimanhas ofensivas do capital sobre o trabalho.

Organizações sólidas intelectualmente, críticas politicamente, autônomas, éticas, com capacidade de mobilização e de construção de hegemonia.

Portadora dessas qualidades, a Abepss chega aos 65 anos de sua criação como patrimônio do Serviço Social Brasileiro. Seu fortalecimento torna-se tanto um dever como um compromisso das unidades de formação acadêmica e da categoria profissional. 